\title{
Formação permanente de professores: um estudo inspirado em Paulo Freire com docentes dos anos iniciais do Ensino Fundamental
}

\author{
SOARES, Maria Perpétua do Socorro Beserra (Brasil, Piauí, Teresina) ${ }^{1^{*}}$ \\ ${ }^{1}$ Universidade Federal do Piauí \\ ORCID ID: http://orcid.org/0000-0002-7452-454X
}

\begin{abstract}
Resumo
O presente artigo apresenta os resultados de uma pesquisa acerca da formação permanente de professores dos anos iniciais do Ensino Fundamental em uma escola da rede pública da cidade de São Paulo, cujo objetivo geral é analisar os alcances e limites da formação permanente de professores para a prática pedagógica comprometida com a construção de uma escola democrática. $O$ aporte teórico fundamenta-se na Pedagogia de Paulo Freire (2001, 2013b, 2015, 2016), Imbernón $(2009,2010)$ e Saul (2010). A investigação é de natureza qualitativa de acordo com Chizzotti (2005), com estudo bibliográfico, pesquisa de campo e documental. Os resultados da pesquisa revelam que há uma forte presença de dimensões da formação permanente, materializando princípios como a escuta, o diálogo, a participação e o movimento de ação-reflexão-ação, evidenciado nos documentos, entrevistas realizadas, observações, encontros de formação e reunião de pais e mestres.
\end{abstract}

\section{Palavras-chave}

Formação permanente de professores. Paulo Freire. Escola democrática.

\section{Permanent formation of tutors: a study inspired in Paulo Freire with teachers of early years of basic education}

\begin{abstract}
This article presents the results of a research about permanent formation of teachers of early years of fundamental teaching of a public district school of a city of São Paulo-SP; whose general objective is to analyze scopes and limits of permanent formation of teachers to a pedagogical practice committed to building a democratic school. The theoretical contributions is based on the pedagogy of Paulo Freire (2001, 2013b, 2015, and 2016), Imbernón (2009, 2010), and Saul (2010). The nature of the investigation is qualitative and follows Chizzotti (2005) with bibliographic study, field and documentary research. The results of the research show a strong presence of dimensions of permanent formation; materializing principles as the hearing, the dialog, the participation and the movement of action-reflection-action, demonstrated on documents, interviews done, observations, formation meetings and parent-teaching conference.
\end{abstract}

\section{Keywords}

Permanent formation of teachers. Paulo Freire. Democratic school. 


\title{
Formación permanente de profesores: un estudio inspirado en Paulo Freire con maestros de los años iniciales de Enseñanza Fundamental
}

\begin{abstract}
Resumen
El presente artículo presenta los resultados de una pesquisa acerca de la formación permanente de profesores de los años iniciales de la Enseñanza Fundamental en una escuela de rede pública de la ciudad de São Paulo, cuyo objetivo general es analizar los alcances y límites de la formación permanente de profesores para la práctica pedagógica comprometida con la construcción de una escuela democrática. El aporte teórico se fundamenta en la Pedagogía de Paulo Freire $(2001,2013 b, 2015,2016)$, Imbernón (2009, 2010) y Saul (2010). La investigación es de naturaleza cualitativa de acuerdo con Chizzotti (2005), con estudio bibliográfico, pesquisa de campo y documental. Los resultados de la pesquisa revelan que hay una fuerte presencia de dimensiones de la formación permanente, materializando principios como la escucha, el diálogo, la participación y el movimiento de acción-reflexión-acción, evidenciado en los documentos, entrevistas realizadas, observaciones, encuentros de formación y reunión de padres y maestros.
\end{abstract}

Palabras clave

Formación permanente de profesores. Paulo Freire. Escuela democrática.

\section{INTRODUÇÃO}

O artigo visa apresentar os resultados de uma pesquisa sobre a formação permanente de professores dos anos iniciais do Ensino Fundamental em uma escola da rede pública da cidade de São Paulo (SP) e tem como objetivo geral analisar os alcances e os limites da formação permanente de professores para a prática pedagógica comprometida com a construção de uma escola democrática. Para embasarmos as reflexões sobre formação permanente de professores, contamos principalmente com a Pedagogia de Paulo Freire (2001, 2013b, 2015, 2016), além dos estudos de Imbernón (2009, 2010) e Saul (2010).

O presente estudo pretende contribuir com reflexões e análises acerca da formação de professores, compreendendo-a como um momento essencial e privilegiado para refletir sobre a prática, principalmente no contexto atual de rápidas mudanças, característica da sociedade da informação e do conhecimento, decorrente dos avanços tecnológicos e, por conseguinte, das alterações socioculturais e econômicas das últimas décadas. 
As transformações contínuas da sociedade contemporânea produzem impactos no cenário educacional, provocando nos(as) educadores(as) incertezas e inseguranças em relação ao que se exige de um novo perfil docente para enfrentar os desafios do momento atual, como formação continuada, autonomia, trabalho coletivo, capacidade de interagir com os alunos, produzir conhecimentos sistematizados e formar cidadãos críticos, criativos, participativos, dentre outros. Por sua vez, os conhecimentos adquiridos com o processo de formação docente não podem ficar cristalizados, especialmente na realidade atual, marcada por contínuas transformações.

Por conseguinte, os(as) professores(as) precisam tomar consciência da importância e da necessidade da formação para atender às exigências da sociedade atual. Importa ressaltar que a formação é de responsabilidade não apenas individual, mas cabe, sobretudo, às instituições formadoras. É preciso repensar a formação de professores, principalmente quando se configura como ações isoladas, fragmentadas e desarticuladas da prática, que não partem das reais necessidades e dos problemas vivenciados pelos(as) educadores(as) no seu fazer cotidiano.

Vale salientar que as ações formativas para os(as) professores(as) dos anos iniciais do Ensino Fundamental, promovidas pelas secretarias de educação municipais e estaduais ou pelas universidades, de modo geral, não têm contemplado as reais necessidades do contexto escolar. Essas ações, em certa medida, têm se caracterizado como atividades esporádicas com caráter de treinamento, reciclagem, aperfeiçoamento em formato de cursos, seminários, palestras e oficinas com caráter aligeirado ou ainda de matriz tradicional, por reconhecer-se que tais iniciativas possam suprir possíveis falhas e lacunas da formação inicial.

Geralmente os programas de formação de professores já vêm preestabelecidos pelas instituições formadoras, pelas secretarias de educação e, muitas vezes, desconsideram as necessidades e as dificuldades dos(as) professores(as) em processo de formação. Na maioria das ações formativas tem predominado uma formação com base na transmissão de conhecimentos, métodos e técnicas por meio de teorias repassadas de maneira descontextualizada, que não levam em conta as reais necessidades e as situações problemáticas dos(as) professores(as), o que os impede de serem sujeitos em seu processo formativo e inibe seu desenvolvimento profissional. 
Consideramos ainda que a maioria das ações formativas volta-se para a realização de palestras, cursos, seminários e oficinas e utiliza métodos transmissivos, de caráter bancário, com temas e conteúdos que não refletem as necessidades formativas dos(as) educadores(as). Nesse sentido, é preciso romper com os modelos tradicionais de formação, que desconsideram a realidade dos(as) professores(as) e se distanciam dela, e criar práticas de formação centradas na escola e pautadas nas suas necessidades e dificuldades.

Contrariamente a essa concepção, defende-se uma formação que não seja transmissiva no que se refere aos métodos, às técnicas e ao acúmulo de conhecimentos. Uma formação humana, dialógica, participativa, que conceba o(a) educador(a) como sujeito da sua formação, e não como objeto; que valorize a reflexão constante do seu saber/fazer, da sua prática pedagógica, de forma problematizadora, contextualizada e pautada no movimento dialético de ação-reflexão-ação. Essa formação possibilita ao(à) educador(a) desenvolver uma postura crítica frente à realidade do seu tempo, para captar as suas reais necessidades e dificuldades, na busca pela transformação das suas práticas.

A esse respeito, Imbernón (2010) acredita que a formação de professores baseada em situações problemáticas, centradas nos problemas da prática, responde às necessidades definidas da escola. Para o autor, a instituição educativa se transforma em um espaço de formação prioritário, mediante projetos ou pesquisas-ações. Nessa concepção, "[...] a escola passa a ser foco do processo de ação-reflexão-ação como unidade básica de mudança, desenvolvimento e melhoria" (IMBERNÓN, 2010, p. 54). Imbernón (2009, p. 42) ainda ressalta que "[...] a formação por si só consegue muito pouco se não estiver aliada a mudanças do contexto, da organização, de gestão e de relações de poder entre os professores".

É importante superar as propostas de formação rígidas, descontextualizadas, que não propiciam e não criam espaços para a reflexão, uma formação segundo o modelo de pacotes impostos aos(às) professores(as), que impede a consciência crítica e criadora e os torna seres acomodados, ajustados, inviabilizando a autonomia 
docente. Nesse sentido, Freire ${ }^{1}$ (2008, p. 15-16) propõe que se faça a denúncia de situações opressoras.

É preciso gritar alto que, ao lado de sua atuação no sindicato, a formação científica das professoras iluminada por sua clareza política, sua capacidade, seu gosto de saber mais, sua curiosidade sempre desperta são dos melhores instrumentos políticos na defesa de seus interesses e de seus direitos.

A formação, sob essa óptica, é um processo de desenvolvimento, ao longo da vida do(a) educador(a). Tem uma dimensão ética, política e profissional, uma vez que o(a) educador(a) deve se preparar, antes mesmo de iniciar a docência. A dimensão ética consiste em refletir o sentido do que se faz, da sua capacidade de valorar, de escolher, de decidir, de agir e de intervir. No seu percurso pessoal/profissional, o(a) professor(a) constrói valores, regras, normas, conhecimentos, ideias. A dimensão política é o reconhecimento de que a educação é um ato político, portanto a educação não é neutra. Há que se ter clareza de questões fundamentais: a favor de quem e do que, contra quem e contra o que fazemos a educação. Essa dimensão tem o compromisso com a construção da cidadania, da democracia e da emancipação de homens e mulheres.

Quanto à dimensão profissional, a profissão docente requer uma busca permanente pela formação. Estar num movimento de procura implica ter a consciência de que somos seres incompletos e não podemos parar de aprender, de estudar, de pesquisar, de interrogar e de problematizar a realidade. Portanto, a investigação realizada na construção deste estudo buscou responder à questão norteadora: "Que contribuições a formação permanente dos professores tem oferecido para a prática pedagógica do coletivo de docentes dos anos iniciais do Ensino Fundamental de uma escola da rede pública municipal situada no bairro Jaraguá-SP, tendo em vista a construção de uma escola democrática?".

1 O momento atual vivido no Brasil é de ataques constantes e distorções da obra e do pensamento de Paulo Freire, reconhecido como o maior educador do século XX, por ser autor de uma pedagogia em favor da libertação dos oprimidos, que tem como horizonte os princípios de liberdade, autonomia, justiça social e democracia. Por essa razão, Paulo Freire tem sido duramente combatido. As suas ideias inspiraram e continuam inspirando educadores e educadoras progressistas ao redor do mundo e todos aqueles que tentam organizar e construir ações coletivas com uma perspectiva política de emancipação e transformação dos sujeitos.

Educação \& Formação, Fortaleza, v. 5, n. 13, p. 151-171, jan./abr. 2020

DOI: https://doi.org/10.25053/redufor.v5i13.1271

http://seer.uece.br/redufor 


\title{
2 A FORMAÇÃO DE EDUCADORES NA PERSPECTIVA DE PAULO FREIRE
}

Neste estudo, o ponto de partida é a concepção do ser humano como inconcluso, inacabado, numa realidade que também é histórica e, portanto, inacabada. $O$ ser humano, como ativo e curioso, tem condição de educar-se. A educação não se esgota, porque a natureza humana não se esgota, e o ser humano está num incessante processo de formação.

Nessa perspectiva, a formação de educadores é entendida neste texto da mesma forma que na acepção de Freire, fundamentada na consciência do inacabamento do ser humano e na sua vocação ontológica de "Ser Mais", uma vez que onde há vida, há inacabamento. Freire (2015, p. 25) assim propõe a formação permanente de educadores:

\begin{abstract}
A educação é permanente não porque certa linha ideológica ou certa posição política ou certo interesse econômico o exijam. A educação é permanente na razão, de um lado, da finitude do ser humano, de outro, da consciência que ele tem de sua finitude. Mais ainda, pelo fato de, ao longo da história, ter incorporado à sua natureza não apenas saber que vivia, mas saber que sabia e, assim, saber que podia saber mais. A educação e a formação permanente se fundam aí.
\end{abstract}

O autor concebe a formação do educador como permanente, o que implica compreender o ser humano como inconcluso e finito. A consciência do inacabamento e da incompletude dos homens e das mulheres propicia infinitas possibilidades e projetos a serem realizados na busca incessante do "Ser Mais". Isso torna possíveis a educação e a formação, ao longo da sua existência.

Nessa direção, Freire (2001) defendia a formação permanente de professores no âmbito da própria escola, com pequenos grupos de educadores(as) ou grupos maiores, fundamentados no movimento de ação-reflexão-ação dos(as)educadores(as) que atuam nas escolas. Tal formação compreende a análise da prática pedagógica, levando em conta a reflexão sobre a prática e a reflexão teórica.

Formar professores na perspectiva permanente contribui para a educação problematizadora, capaz de formar sujeitos que consigam fazer uma leitura crítica do mundo, do contexto, buscando superar a concepção de formação docente que reduz a autonomia do(a) professor(a) sobre o seu trabalho, sua capacidade de refletir 
criticamente a realidade na qual está inserido(a). Contribui também para a construção de uma escola democrática.

A formação permanente, na perspectiva freireana, constitui-se como princípio e prática da formação capaz de desvelar as ideologias, porque é problematizadora, crítica e busca continuamente uma ação transformadora da realidade. Esse entendimento leva a questionar a afirmação de que o professor está formado apenas com a conclusão de um curso superior e indica que ele se encontra em constante processo de formação, com possibilidade de construir conhecimentos, refletir sobre a prática, trocar experiências com os pares. Sendo o professor um ser inconcluso, não sabe tudo, mas também não ignora tudo, por essa razão pode aprender-ensinar com outros. A esse respeito, Freire (2016, p. 25) afirma que "[...] quem ensina aprende ao ensinar e quem aprende ensina ao aprender".

Ao assumir o princípio do inacabamento humano, a busca por ações formativas dos professores, pautadas na perspectiva freireana, poderá contribuir para uma educação problematizadora, que ganha vida em ações e relações humanizadoras e auxilia os(as) professores(as) na gestão da sua própria formação, com a capacidade de sentir-se sujeitos da sua própria formação e da constituição de seus conhecimentos, e não apenas como pessoas que transmitem e reproduzem o que outros pensaram e construíram. A esse respeito, Freire (2016, p. 24-25, grifos do autor) afirma:

\footnotetext{
Se, na experiência da minha formação, que deve ser permanente, começo por aceitar que o formador é o sujeito em relação a quem me considero o objeto, que ele é o sujeito que me forma e eu, o objeto por ele formado, me considero como um paciente que recebe os conhecimentos - conteúdos - acumulados pelo sujeito que sabe e que são a mim transferidos. Nesta forma de compreender e de viver o processo formador, eu, objeto agora, terei a possibilidade, amanhã, de me tornar o falso sujeito da 'formação' do futuro objeto de meu ato formador.
}

$\mathrm{Na}$ perspectiva freireana, a formação de professores não busca apenas a qualificação por meio da certificação do professor para o exercício da docência. Não visa a meras atualizações científicas, pedagógicas e didáticas, mas, sobretudo, a uma formação de caráter permanente, que considere o professor como sujeito do processo, propiciando condições favoráveis para refletir criticamente sobre suas práticas, 
incertezas e curiosidades, com possibilidades de fazer uma leitura do contexto no qual está inserido, na busca da superação das condições opressoras.

De acordo com Freire (2016), a essência da formação permanente de educadores é a reflexão sobre a prática para melhorá-la. Nesse sentido, tal formação vai além do treinamento, do aperfeiçoamento, da reciclagem e da capacitação, uma vez que é comprometida com a reflexão sobre a prática numa perspectiva crítica e transformadora.

Quando assumiu o cargo de secretário da educação, no município de São Paulo, no período 1989 a 1991. Paulo Freire tinha como objetivo implementar uma política curricular com compromisso de construir uma escola pública popular, democrática, autônoma, com a participação ativa de professores(as), alunos(as), gestores(as) e a família.

O presente estudo foi desenvolvido com a elaboração da trama conceitual freireana, uma construção teórico-metodológica que tem dupla finalidade. Segundo Saul A. M. e Saul A. (2013), a primeira delas é ajudar o pesquisador a visualizar como os conceitos freireanos podem ser articulados para atender aos propósitos de sua pesquisa, como compreender um fenômeno ou uma situação, propor ou avaliar políticas ou práticas educativas. Quanto à segunda, tem uma função didática e pode ser utilizada em situações de ensino-aprendizagem para a compreensão e o aprofundamento da obra de Paulo Freire.

A trama conceitual constitui uma forma de trabalhar a relação dos conceitos apresentados na obra de Freire, como também uma maneira de compreender os conceitos de modo relacional, sem olhar as palavras isoladamente, mas de forma totalizante e dinâmica. A trama compreende um conceito central, que, neste estudo, é a formação permanente. Os conceitos são representados por setas e palavras que buscam uma relação. O tema central está relacionado aos conceitos de consciência do inacabamento do homem, da busca do "Ser Mais", que necessita da escuta, exige o diálogo, requer a participação, envolve o movimento ação-reflexão-ação e busca a transformação.

A seguir, a representação da trama conceitual freireana elaborada a partir do conceito formação permanente: 
Figura 1 - Trama conceitual freireana

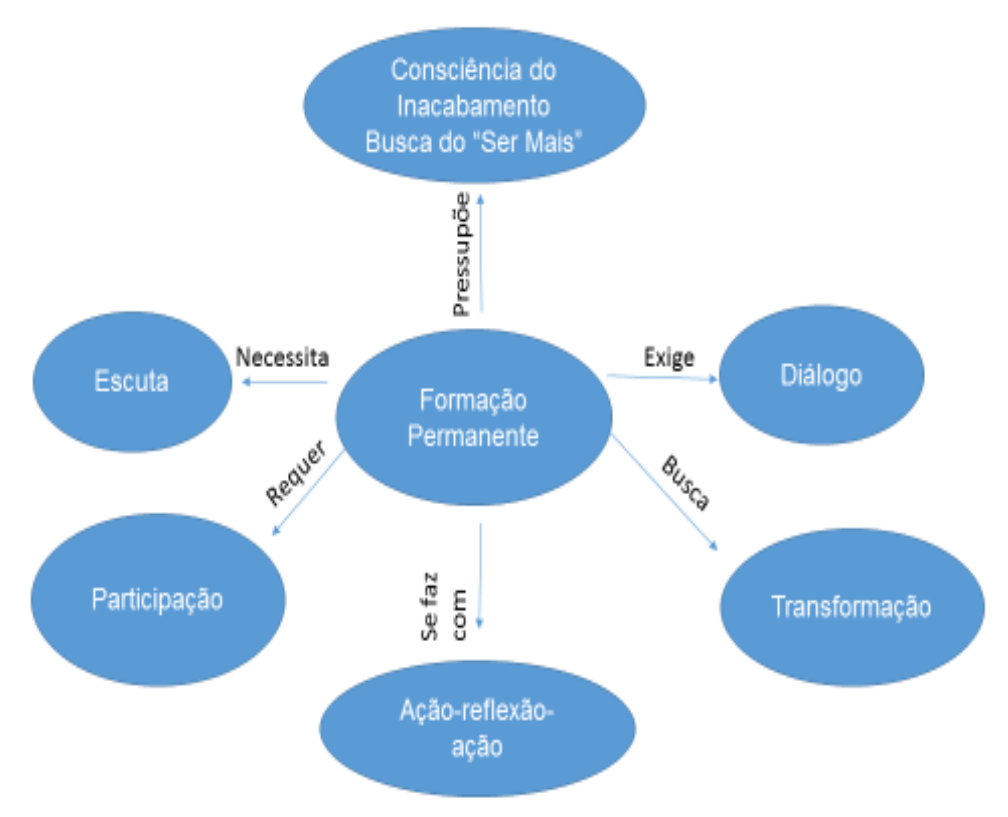

Fonte: Elaboração própria (2019).

A formação permanente tem por fundamento entender e reconhecer 0 inacabamento e a incompletude dos seres humanos, que os impulsiona à busca do "Ser Mais". O processo de formação de professores é constante, não se encerra com a conclusão do curso de graduação ou em qualquer outro determinado período de tempo.

A categoria "escuta" é um dos saberes fundamentais e necessários à prática educativa proposta por Freire na Pedagogia da autonomia (2016). O(a) educador(a) que escuta aprende e transforma o seu discurso dirigido ao(a) educando(a), ao falar com ele(a). Escutar vai mais além da possibilidade auditiva de cada um. Para Freire (2016, p. 117), escuta significa "[...] a disponibilidade permanente por parte do sujeito que escuta para a abertura à fala do outro, ao gesto do outro, às diferenças do outro".

Freire (2001, p. 43) alerta que "[...] é preciso que falem a nós, de como veem a escola, de como gostariam que ela fosse; que nos digam algo sobre o que se ensina ou não se ensina na escola, de como se ensina. Ninguém democratiza a escola sozinho, a partir do gabinete do secretário". Desse modo, um dos desafios da formação de educadores é a inclusão, nas suas agendas, da prática da escuta dos anseios, dos interesses e das inquietações, valorizando diferentes linguagens e gestos. 
Em sintonia com o pensamento de Freire, Saul (2010, p. 160) entende que "[...] saber escutar é condição para o desenvolvimento de uma prática educativa democrática". A escuta possibilita a capacidade de ouvir pessoas diferentes. A compreensão e o respeito do(a) educador(a) aos conhecimentos do(a) educando(a) são um ato de escuta, a partir da leitura de mundo que ele(a) tem. Essa prática de saber escutar exige do(a) educador(a) a aquisição de novos saberes, como a humildade, a tolerância, a solidariedade e o respeito ao outro.

$\mathrm{Na}$ concepção de Freire (2013b, p. 109), “[...] o diálogo é este encontro dos homens, mediatizados pelo mundo, para pronunciá-lo, não se esgotando, portanto, na relação eu-tu". O diálogo pertence à natureza do ser humano, é uma condição existencial. Dizer a palavra não é privilégio de alguns homens e mulheres, mas direito de todos(as). A relação dialógica proposta por Freire é baseada no amor, que é um ato de coragem, compromisso, responsabilidade e comprometimento com a causa da libertação. $O$ diálogo exige também a confiança em si e nos outros para a pronúncia do mundo. A falta de confiança inviabiliza o diálogo.

Para Freire e Shor (2008, p. 122-127):

[...] o diálogo deve ser entendido como algo que faz parte da própria natureza histórica dos seres humanos [...]. O diálogo é o momento em que os humanos se encontram para refletir sobre sua realidade tal como a fazem e re-fazem. [...]. O diálogo não existe num vácuo político. Para alcançar os objetivos da transformação, o diálogo implica responsabilidade, direcionamento, determinação, disciplina, objetivos.

O diálogo, na concepção de Freire e Shor (2008), constitui o centro da prática educativa que se pretende democrática, crítica, problematizadora e transformadora, uma vez que, na relação dialógica, os sujeitos confrontam argumentos, questionam, discutem, partilham saberes, experiências e vivências. O diálogo contribui para a formação de sujeitos livres, criativos, curiosos, indagadores e autônomos nos diversos contextos educacionais.

Segundo Freire (2001, p. 127), a participação está relacionada a compartilhar decisões, dividir o poder e ter a plena convicção política de seus atos. Significa que todos possam ter voz nos diferentes segmentos do poder. Para o autor:

[...] participar é bem mais do que, certos fins de semana, 'oferecer' aos pais a oportunidade de, reparando deteriorações, estragos das escolas,

Educação \& Formação, Fortaleza, v. 5, n. 13, p. 151-171, jan./abr. 2020

DOI: https://doi.org/10.25053/redufor.v5i13.1271

http://seer.uece.br/redufor 
fazer as obrigações do próprio Estado [...]. Participar é discutir, é ter voz, ganhando-a na política educacional das escolas, na organização de seus orçamentos.

A participação não pode reduzir-se à prestação de serviços esporádicos para minimizar a responsabilidade do Estado de cumprir as suas funções. A autonomia da escola não implica o Estado omitir-se do seu dever de oferecer educação de qualidade e em volume suficiente para atender à demanda social.

A participação popular é uma ferramenta capaz de romper com a tradição de que só a elite é competente e sabe as necessidades e os interesses da sociedade como um todo. Freire (2001) era contra a convocação do povo na escola apenas para receber instruções, ameaças, repreensões e punições. Para ele, as classes populares precisam participar coletivamente na construção de um saber que leve em conta as suas necessidades e interesses.

Podemos afirmar que a categoria ação-reflexão-ação é fundamental no pensamento de Freire. A expressão significa o binômio da unidade dialética da práxis, ou seja, fora da práxis o conhecimento resulta idealista e o fazer torna-se algo meramente mecânico, sem reflexão. Para Freire (2013a, p. 30), "[...] o homem é um ser da práxis, da ação e da reflexão", isso significa que o ser humano é capaz de objetivar, apreender e penetrar a realidade, desdobrando-se na ação transformadora do mundo. O ser humano, como ser de práxis, cria um mundo histórico-cultural para enfrentar os desafios no transcurso da sua existência, procura soluções críticas e criativas, atuando e transformando a realidade, buscando continuamente, por meio do trabalho e da ação, propiciar condições de melhoria de vida na sociedade.

A formação permanente, na perspectiva freireana, é pautada no processo de ação-reflexão-ação, em que o sujeito seja capaz de desenvolver uma postura crítica frente à realidade do seu tempo, considerando que ele é um ser histórico-social em constante construção do conhecimento.

Quanto à categoria transformação, destaca-se o seu caráter de comprometimento e engajamento na luta em favor da causa dos oprimidos. De acordo com Freire (1994, p. 18), "[...] a transformação é entendida como um ato de criação dos homens". Transformar a realidade e a prática pedagógica é condição e um dos objetivos das ações de formação permanente de professores. 
A prática pedagógica transforma-se no "chão da escola", lugar e solo fértil para que efetivamente ocorram as mudanças necessárias. A formação no âmbito da escola precisa criar condições e oportunidades para desencadear a reflexão dos(as) educadores(as) sobre as suas concepções e práticas educativas, para que possam ressignificar a sua ação pedagógica. Os(As) professores(as) precisam ter um espírito de descoberta, uma postura crítica para repensar a sua prática e perceber os aspectos que precisam de análise e aprofundamento.

\section{METODOLOGIA}

Neste estudo, optamos pela pesquisa qualitativa, que possibilita interpretar os significados que as pessoas atribuem aos fatos e aos fenômenos. De acordo com Chizzotti (2005, p. 79), "[...] a abordagem qualitativa parte do fundamento de que há uma relação dinâmica entre o mundo real e o sujeito, uma interdependência viva entre o sujeito e o objeto, um vínculo indissociável entre o mundo objetivo e a subjetividade do sujeito". Dessa forma, o conhecimento não se reduz a um rol de dados isolados, conectados por uma teoria explicativa, pois o sujeito-observador é parte integrante do processo de conhecimento, interpreta os fenômenos e atribui-Ihes um significado.

A pesquisa qualitativa contempla uma diversidade de dados empíricos, como análise de documentos, notas de campo, entrevistas, observações, com a finalidade de compreender ou interpretar os fenômenos em seus cenários naturais e os significados que as pessoas a eles atribuem.

Nesta investigação, utilizamos três técnicas integradas: a observação participante, por compreender que o pesquisador tem sempre um grau de interação com a situação estudada, afetando-a e sendo afetado por ela; a entrevista semiestruturada, por dar maior flexibilidade entre o entrevistador e o entrevistado, elaborada a partir das observações; e, por último, a análise documental, considerada uma técnica valiosa, pois os documentos constituem uma fonte rica e estável de informações, podendo ser consultados diversas vezes.

As observações foram realizadas na escola pesquisada, nos encontros de formação: Jornada Especial Integral de Formação (JEIF) e Projeto Especial de Ação 
(PEA); nas reuniões pedagógicas; nas reuniões de pais e mestres e da prática pedagógica, no período de agosto a novembro de 2015.

As entrevistas semiestruturadas foram realizadas com um diretor, duas coordenadoras pedagógicas e quatro professoras dos anos iniciais do Ensino Fundamental de uma escola da rede pública situada no bairro Jaraguá, na cidade de São Paulo (SP). Os documentos analisados foram: o Projeto Político-Pedagógico (PPP) e o Projeto Especial de Ação (PEA), cujo tema é "Linguagens, Tecnologia e Convivência numa Cidade Educadora".

\section{ANÁLISE E DISCUSSÃO DOS RESULTADOS}

Para descrever, explicar e compreender o fenômeno pesquisado na sua amplitude, os dados foram produzidos em momentos variados e com diversas fontes de informações, recorrendo-se à triangulação dos instrumentos para sua obtenção: documentos, observações e entrevistas. Conforme Denzin (1978), a triangulação de dados consiste em coletar dados em diferentes períodos e de diversas fontes, para obter uma detalhada descrição dos fenômenos.

Os dados foram organizados em eixos, a partir das categorias elencadas na trama conceitual freireana, constituída com base em estudos da obra do autor. Os eixos temáticos foram assim definidos: a formação como um processo inacabado e transformador; a escuta e o diálogo na elaboração do PPP e nas formações de professores: um processo crítico-transformador; a participação da comunidade nas ações de formação; o movimento de ação-reflexão-ação na (trans)formação e nas práticas das professoras.

A partir do primeiro eixo - a formação como um processo inacabado e transformador -, foi constatado o princípio da consciência e do reconhecimento do ser humano como inacabado, evidenciado nos relatos das coordenadoras e das professoras entrevistadas.

Eu penso que a gente está em formação até o dia da nossa morte, tanto como ser humano como profissional. Não podemos dizer que o professor está formado. O ser humano nunca vai poder dizer: 'Estou pronto', ele está sempre em processo, pois a formação é inacabada. (COORDENADORA 1). 
Acredito que a gente nunca está formada. A formação não termina, eu acredito nisso, porque na hora que a gente terminar e falar: 'Eu me formei, acabou', pode sair da área da Educação, procurar outro emprego. (COORDENADORA 2).

Eu acredito na formação do professor, na formação permanente do ser humano, o tempo todo, pois a formação é um processo inacabado, e o professor nunca para de estudar, de buscar, de pesquisar e de aprender. (PROFESSORA 1).

As participantes destacaram que o(a) professor(a) nunca está pronto(a), pois está em movimento de formação constante, aprendendo-ensinando, fazendo e refazendo-se continuamente, em razão da necessidade de buscar o conhecimento. Reconheceram que a formação é um processo ininterrupto, em razão da contínua exigência do ser humano de aprender mais, dada a sua condição de incompletude e inconclusão, duas características que, na perspectiva freireana, constituem o princípio fundante da formação permanente.

Em relação à concepção de formação de professores, as vozes dos sujeitos revelaram as seguintes compreensões:

Ela tem que ser uma formação permanente, baseada sempre na reflexão a respeito da própria prática [...]. Então, por isso que a gente tenta sempre pautar a formação nas demandas que a gente tem diariamente dentro da escola. (COORDENADORA 1).

Para mim, a formação de professores são as trocas que temos durante os nossos quatro encontros semanais de JEIF, onde consolidamos a nossa formação, enquanto grupo da escola, baseados nas discussões e reflexões sobre as necessidades dos professores sobre a prática. (COORDENADORA 2).

As vozes dos sujeitos anunciaram a necessidade de as ações formativas pautarem-se na prática dos professores, nos problemas e nas dificuldades com que eles se deparam na sala de aula, pois, na maioria das vezes, a formação inicial não consegue dar conta dessa complexidade. Por essa razão, é de fundamental importância a formação permanente de educadores na perspectiva freireana.

Tomando por elemento norteador o segundo eixo - a escuta e o diálogo na elaboração do PPP e nas formações de professores: um processo crítico-transformador -, são apresentadas as categorias escuta e diálogo, no PPP da Escola, da seguinte forma:

Educação \& Formação, Fortaleza, v. 5, n. 13, p. 151-171, jan./abr. 2020

DOI: https://doi.org/10.25053/redufor.v5i13.1271

http://seer.uece.br/redufor 
Temos a escuta e o olhar atentos às necessidades detectadas no cotidiano e, em especial, nas assembleias de alunos, nas quais exercitam o diálogo e a cidadania, num coletivo mais amplo que a sala de aula, na eleição dos Representantes de Classe e na eleição do Grêmio Estudantil. (SÃO PAULO [Município], 2014, p. 15, grifos nossos).

Que os alunos possam produzir conhecimentos que contribuam para a transformação da sociedade, a superação das dificuldades e a humanização das relações entre os homens, utilizando o diálogo como forma de mediar conflitos e de tomar decisões coletivas. (SÃO PAULO [Município], 2014, p. 13, grifo nosso).

A escuta e o diálogo são princípios ressaltados no PPP da Escola investigada como condições importantes e necessárias à finalidade de identificar e buscar respostas coletivas às necessidades e aos problemas vivenciados no cotidiano escolar.

Como base de sustentação do diálogo, o PPP assume uma visão de conhecimento como sendo construído, e não meramente transmitido e a serviço da transformação. O diálogo foi estabelecido nas ações de formação, uma vez que ocorreu por meio da confiança, da humildade e do respeito ao outro, às suas ideias, aos seus valores e saberes. Freire alerta (2013a, p. 51) que "[...] ser dialógico é não invadir, é não manipular, é não 'sloganizar'. Ser dialógico é empenhar-se na transformação constante da realidade".

O diálogo, como instrumento de comunicação, foi encontrado nas reuniões de formação (JEIF e PEA):

A Coordenadora 1 faz um comentário sobre os contos de fadas com as princesas negras. Nós temos que pesquisar o assunto, não está pronto, temos que construir. Nas nossas aulas podemos mostrar aos nossos alunos que as princesas negras são lindas. Cada povo tem a sua beleza, a sua cultura, os seus costumes, os seus valores, as suas tradições, e esse padrão que foi imposto de beleza deve ser questionado e criticado. Ressalto mais uma vez que nós temos que repensar o nosso currículo para o próximo ano. Professora 1 diz: 'Eu penso que o caminho é o da reflexão e criticidade acerca dessas questões'. A Coordenadora finaliza a reunião. (DIÁRIO DE CAMPO, 10/11/2015).

O diálogo verdadeiro não é uma imposição, em que uma pessoa se considera a detentora da palavra, da fala, e os outros não têm a liberdade de dizer sua palavra e apenas ouvem, sem se pronunciar. O diálogo verdadeiro consiste na relação coletiva, no encontro em que todos possam comunicar-se. Assim, o exercício da comunicação dialógica contribui para desenvolver as relações democráticas na escola e na sociedade. 
A partir do terceiro eixo - a participação da comunidade nas ações de formação -, foi constatado que a prática da participação presenciada na escola se dá de formas variadas: na elaboração de documentos, nos encontros de formação, nas reuniões, no planejamento e na realização de festas, passeios e visitas e no envolvimento com as atividades realizadas, contribuindo com a construção de uma escola democrática.

A participação dos professores foi apontada como uma categoria importante nas falas dos sujeitos:

\begin{abstract}
A participação dos professores é importante na tomada de decisões, na implementação do Projeto Político-Pedagógico, nas reuniões de formação de professores e nos projetos interdisciplinares e transdisciplinares da escola. (DIRETOR).
\end{abstract}

Quando nós precisamos pensar em algo para a escola, por exemplo, nas necessidades da escola, nas necessidades dos alunos, nas nossas necessidades, na melhor forma de montagem de salas, montagem de turmas, então a gente decide isso participando dos momentos coletivos. Então, os encontros de formação são importantes na tomada de decisões. (PROFESSORA 2).

Nas falas dos entrevistados, fica evidente a compreensão de que o trabalho coletivo propicia a discussão em torno das demandas relacionadas a lacunas decorrentes na formação, bem como aquelas advindas do cotidiano escolar, na tomada de decisões, na montagem de turmas. Participar significa ter direito, discutir, compartilhar decisões coletivas e contribuir com seus desdobramentos e consequências.

No âmbito da sala de aula, os alunos participaram, emitindo suas opiniões, seus saberes, através da construção de desenhos que expressam a sua imaginação e emoções. Quanto à participação da família na reunião de pais e mestres, aconteceu de forma tímida, porque foram poucos os que conseguiram expor as suas ideias, opiniões, sugestões e críticas quanto aos assuntos tratados: a importância de a família conhecer o PPP da escola; a participação no Conselho de Escola; o combate ao mosquito da dengue, zika e chikungunya; e o uniforme do aluno.

Participar significa "tomar parte" no processo, emitir uma opinião, concordar ou discordar - significa tomar decisões. Fica evidente aí a importância de que a família tome consciência do valor de sua participação mais ativa nas decisões da escola. A gestão da escola precisa envidar esforços para conscientizar a família da sua participação mais efetiva, por meio de ações que promovam o seu envolvimento. 
As falas dos sujeitos revelaram que a formação desenvolvida na unidade escolar contribui para a construção de uma escola democrática.

A JEIF é determinante na construção de uma escola democrática, porque representa um espaço de tomada de decisões, de compartilhamento das nossas experiências, das nossas angústias, dos nossos sonhos, das nossas vitórias [...]. (COORDENADORA 1).

A unidade escolar está tentando construir, há 16 anos, uma escola da melhor qualidade possível, democrática. Nós queremos uma escola onde professores, alunos, funcionários e a família possam escolher com autonomia e responsabilidade. (DIRETOR).

A Coordenadora 1 reconhece que a JEIF é relevante na construção de uma escola democrática, por ser um espaço privilegiado de tomada de decisões, de trocas de conhecimento, de compartilhamento de experiências, que visam a combater todas as formas de discriminação e preconceito. O Diretor ressalta a autonomia da escola como fundamental na construção de uma escola democrática. A participação é uma prática que pode ser ampla, vigorosa e constantemente vivenciada, e a escola se constitui em um espaço privilegiado de formação para a participação e o exercício da cidadania.

O PEA ressalta a participação da comunidade na escola investigada. Este excerto do documento citado confirma essa relevância: "[...] a comunidade, por sua vez, deverá ter intensificada sua participação na escola e parceria na vida escolar de seus filhos" (SÃO PAULO [Município], 2015). Na análise do PEA, constatamos que o documento ressalta a participação como um princípio importante, que ganha vida no compartilhamento de ideias, no respeito ao outro, na garantia de igualdade nas decisões e na busca pelo envolvimento do coletivo nas ações delas decorrentes.

O tema do PEA da escola - projeto elaborado pela unidade escolar com a participação do diretor, das coordenadoras pedagógicas e dos(as) professores(as) - na ocasião da pesquisa foi "Linguagens, Tecnologia e Convivência numa Cidade Educadora". A escolha do tema buscou atender às necessidades dos(as) alunos(as) e subsidiar os(as) professores(as) para auxiliar as crianças na questão da capacidade leitora e escritora em todas as áreas do conhecimento e também no uso da tecnologia, ferramenta muito utilizada nos dias atuais.

O quarto e último eixo - o movimento de ação-reflexão-ação na (trans)formação e nas práticas das professoras - foi identificado nas vozes dos sujeitos. 
Toda vez que eu participo dos encontros de formação, percebo que esse movimento de fazer e refazer é algo muito bom, porque reconstrói a prática. [...]. Esse movimento faz com que eu entenda o que é o ensinar, o que é o educar, o que é educação de verdade. (PROFESSORA 2).

Na minha opinião, a formação propicia a reflexão da prática pedagógica. As formações na escola são regadas de espaços para estudar teorias e espaços de prática colocada dentro dessa teoria. Nós somos convidados para fazer esse movimento, a refletir sobre o movimento ação-reflexão-ação na busca da transformação das práticas. (PROFESSORA 3).

Os relatos das professoras revelam a compreensão da formação como um movimento do fazer e refazer constante das práticas e a possibilidade de efetivar mudanças. Elas reconhecem a necessidade de buscar e aprofundar os conhecimentos com a promoção de práticas cada vez melhores; acreditam que a formação propicie a reflexão sobre a prática pedagógica, por meio de discussões e de encontros de formação.

Para Freire (2008), a ação-reflexão-ação constitui a unidade dialética da práxis. A reflexão é o movimento realizado entre o fazer e o pensar, entre o pensar e o fazer. A formação permanente de educadores, em Freire, não prioriza ou valoriza apenas a prática ou a teoria no contexto de formação, não defende ser a teoria primordial na formação e a prática relegada ao segundo plano. Em vez disso, compreende ambas teoria e prática - como componentes de um processo que deve ser visto pela óptica da unidade, em que a existência de uma está subsumida na existência da outra.

\section{CONSIDERAÇÕES FINAIS}

Com base nas reflexões e nas análises deste estudo, podemos afirmar que é fundamental elaborar uma proposta de formação permanente de educadores, que compreenda o ser humano como inconcluso, na perspectiva do "Ser Mais", e realize a leitura da realidade pautada na escuta, no diálogo e na participação da comunidade escolar.

Constatamos que o PPP da escola e do grupo participante do estudo destaca a escuta e o diálogo como princípios balizadores do movimento da Escola, para conhecer os anseios da comunidade em relação à educação, à sociedade, à escola, ao currículo

Educação \& Formação, Fortaleza, v. 5, n. 13, p. 151-171, jan./abr. 2020

DOI: https://doi.org/10.25053/redufor.v5i13.1271

http://seer.uece.br/redufor 
escolar e ao processo ensino-aprendizagem, tendo como horizonte a transformação da Escola.

Nas entrevistas realizadas, percebemos que os sujeitos reconhecem que as trocas de experiências e de vivências e as discussões feitas nos encontros da JEIF adensam a formação e são fundamentais na sua formação permanente e na consolidação do trabalho coletivo.

Durante as observações, identificamos que um dos limites da formação pesquisada no contexto dessa Escola refere-se ao número reduzido de professores(as) que frequentam as ações formativas. Para solucionar esse problema, faz-se necessário organizar o tempo pedagógico, incluindo horário das aulas, de modo a permitir a convergência de horários de planejamento e estudo dos(as) professores(as), mesmo que essa convergência se configure em organizar horários por série/área. É preciso que as ações de formação consigam envolver todos(as) os(as) professores(as) ao mesmo tempo.

A participação, como pronúncia da voz dos(as) educadores(as), em uma perspectiva crítica, foi identificada na elaboração e na implementação do PPP nas formações e em tomada de decisões que visavam a superar inquietações advindas do "chão" da sala de aula.

A análise de documentos, a realização de entrevistas e a observação de encontros de formação e da prática pedagógica permitiram dizer que a materialidade de dimensões que constituem a formação permanente, tais como a escuta, o diálogo, a participação e o movimento de ação-reflexão-ação, apresentou-se com mais vigor no plano das intencionalidades - PPP, PEA e falas dos sujeitos - do que no plano das ações formativas, das reuniões, da sala de aula e da participação da família.

Os resultados desta investigação e os aprendizados advindos deste processo de pesquisa permitiram apresentar/sugerir pontos de reflexão para o aperfeiçoamento das ações de formação de professores da Escola pesquisada.

A formação permanente freireana propõe-se a um caminhar para além do entendimento e da prática de formação, com foco na leitura e no estudo de textos, em geral decididos por aqueles que planejam as ações. Essa concepção é ainda fortemente assumida por secretarias de educação, diretorias regionais, instituições de ensino superior, bem como pelo próprio Ministério da Educação. 
A aproximação, o apoio e a colaboração entre a universidade e a escola, com a participação dos especialistas das diferentes áreas do conhecimento, são importantes para desenvolver ações de formação de áreas específicas de atuação dos(as) professores(as).

Ampliar os espaços para o diálogo, a reflexão e a discussão da família, da comunidade escolar, visando à sua participação mais efetiva, é fundamental nas decisões e nas ações da Escola, nas reuniões de pais e mestres e nas reuniões pedagógicas.

Em síntese, ao lado da formação qualificada de professores aqui delineada, é preciso lutar por melhores condições de trabalho, salários dignos, valorização profissional, espaço-tempo de formação para refletir criticamente sobre a prática, com vistas à construção da autonomia profissional docente.

\section{REFERÊNCIAS}

CHIZZOTTI, A. Pesquisa em ciências humanas e sociais. São Paulo: Cortez, 2005.

DENZIN, N. K. The research act: a theoretical introduction to sociological methods. 2.ed. New York: Mc Graw-Hill, 1978.

FREIRE, P. A educação na cidade. 5. ed. São Paulo: Cortez, 2001.

FREIRE, P. Educação e mudança. 17. ed. Rio de Janeiro: Paz e Terra, 1994.

FREIRE, P. Extensão ou comunicação?. 16. ed. Rio de Janeiro: Paz e Terra, 2013a.

FREIRE, P. Pedagogia da autonomia: saberes necessários à prática educativa. 53. ed. Rio de Janeiro: Paz e Terra, 2016.

FREIRE, P. Pedagogia do oprimido. 54. ed. Rio de Janeiro: Paz e Terra, 2013b.

FREIRE, P. Política e educação: ensaios. 2. ed. São Paulo: Paz e Terra, 2015.

FREIRE, P. Professora sim, tia não: cartas a quem ousa ensinar. São Paulo: Olho d'Água, 2008.

FREIRE, P.; SHOR, I. Medo e ousadia: o cotidiano do professor. Rio de Janeiro: Paz e Terra, 2008.

IMBERNÓN, F. Formação continuada de professores. Porto Alegre: Artmed, 2010. 
IMBERNÓN, F. Formação permanente do professorado: novas tendências. São Paulo: Cortez, 2009.

SÃO PAULO (Município). Secretaria Municipal de Educação. Diretoria Regional de Educação Pirituba. EMEF. Projeto Político-Pedagógico. São Paulo, 2014.

SÃO PAULO (Município). Projeto Especial de Ação - PEA. São Paulo, 2015.

SAUL, A. M. Currículo. In: STRECK, D. R.; REDIN, E.; ZITKOSKI, J. J. (Org.). Dicionário Paulo Freire. 2. ed. rev. ampl. Belo Horizonte: Autêntica, 2010. p. 109-110.

SAUL, A. M.; SAUL, A. Mudar é difícil, mas é possível e urgente: um novo sentido para 0 projeto político-pedagógico da escola. Revista Teias, Rio de Janeiro, v. 14, n. 33, 102120, 2013.

\section{Maria Perpétua do Socorro Beserra Soares (Brasil, Piauí, Teresina)} Universidade Federal do Piauí (UFPI)

Doutora em Educação pela Pontifícia Universidade Católica de São Paulo-PUC/SP. Mestre em Educação pela Universidade Federal do Piauí-UFPI. Especialista em História da Filosofia Contemporânea pela Universidade Federal do Piauí-UFPI. Licenciada em Filosofia pela Universidade Federal do Piauí-UFPI. Licenciada em Letras-Português pela Universidade Estadual do Piauí-UESPI. Professora Adjunta da Universidade Federal do Piauí, Campus Ministro Reis Velloso, Parnaíba-PI.

Lattes: http://lattes.cnpq.br/3681740653052468.

E-mail:socorrob@ufpi.edu.br.

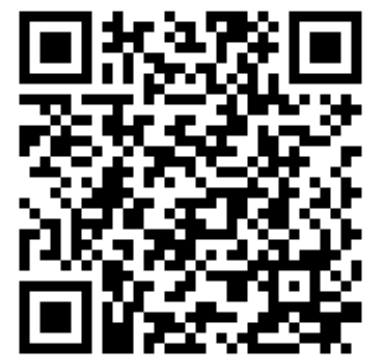

Recebido em 11 de abril de 2019.

Aceito em 08 de julho de 2019. 